\title{
Folliculocystic and Collagen Hamartoma: A Subset of Fibrous Cephalic Plaque
}

\author{
Anita S. Savell ${ }^{1}$, Kyle Norton ${ }^{1}$, Michael R. Heaphy Jr. ${ }^{2,1}$ \\ 1. Dermatology, University of Nevada Reno School of Medicine, Reno, USA 2. Dermatopathology, Skin Cancer and \\ Dermatology Institute, Reno, USA
}

Corresponding author: Anita S. Savell, asavell@med.unr.edu

\begin{abstract}
Tuberous sclerosis complex is known to cause a variety of cutaneous hamartomas, most commonly hypomelanotic macules, angiofibromas, shagreen patches, and fibrous cephalic plaques. In recent years, a new cutaneous hamartoma that bears physical and histological resemblance to fibrous cephalic plaque has been proposed called folliculocystic and collagen hamartoma. The primary difference between the two diagnoses is the histologic presence of infundibular cysts in the latter. However, some authors have called into question if the two diagnoses are truly distinct. In this case report, we present a patient with tuberous sclerosis complex and fibrous cephalic plaque with infundibular cysts and propose that the presence of cysts should be incorporated into the possible histologic features of fibrous cephalic plaque.
\end{abstract}

Review began 09/30/2020 Review ended 05/09/2021 Published 05/12/2021

\section{(c) Copyright 2021}

Savell et al. This is an open access article distributed under the terms of the Creative Commons Attribution License CC-BY 4.0., which permits unrestricted use, distribution, and reproduction in any medium, provided the original author and source are credited.
Categories: Dermatology

Keywords: tuberous sclerosis complex, fibrous cephalic plaque, folliculocystic and collagen hamartoma, hamartoma

\section{Introduction}

Many people with tuberous sclerosis complex (TSC) have cutaneous manifestations: hypomelanotic macules (97.2\%), facial angiofibromas (74.5\%), shagreen patches (48\%), fibrous cephalic plaques (FCPs) (18.9\%), and periungual fibromas (15.1\%) [1]. FCP typically presents as large, smooth-to-bumpy, firm-to-rubbery plaques on the forehead, face, scalp, or neck of patients with TSC [2]. It is histologically characterized by thick collagen deposition with perifollicular fibrosis and may demonstrate increased numbers of dilated vessels [2].

Folliculocystic and collagen hamartoma $(\mathrm{FCCH})$ has been proposed as a new entity associated with TSC. It presents as a complex hamartoma with thick collagen deposition, concentric perifollicular fibrosis, and keratin-filled infundibular cysts [3]. On physical examination, the lesions appear as "large, painless, infiltrated plaques studded with follicular comedo-like openings and cysts containing and draining a keratinous or purulent material" [3] and have been reported on the face, scalp, abdomen, back, and thigh [4]. Since its initial characterization, 12 cases of FCCH have been reported, six of which were from the original report from Torrelo et al. in 2012 [3-9]. Here, we present a case of FCP with infundibular cysts on the scalp and forehead in a young man with a previously established diagnosis of TSC.

\section{Case Presentation}

A 17-year-old male with a known history of TSC and epilepsy presented to the dermatology clinic with multiple angiofibromas on the face and a large, painless exophytic mass on his central forehead. He requested excision due to cosmetic concerns (Figure 1). Microscopic examination of the lesion demonstrated epidermal papillomatosis, cystically dilated hair follicles (Figure $2 A$ ), hyperplastic sebaceous lobules displaced to the lower portions of the dermis by the cystic expansion of the follicular infundibulum (Figure $2 A$ ), and increased vascularity and fibrocytes (Figure $2 B$ ). There was also an expansion of the subcutaneous collagenous tissue which greatly contributed to the nodularity of the lesion clinically (Figure 2C). 


\section{Cureus}

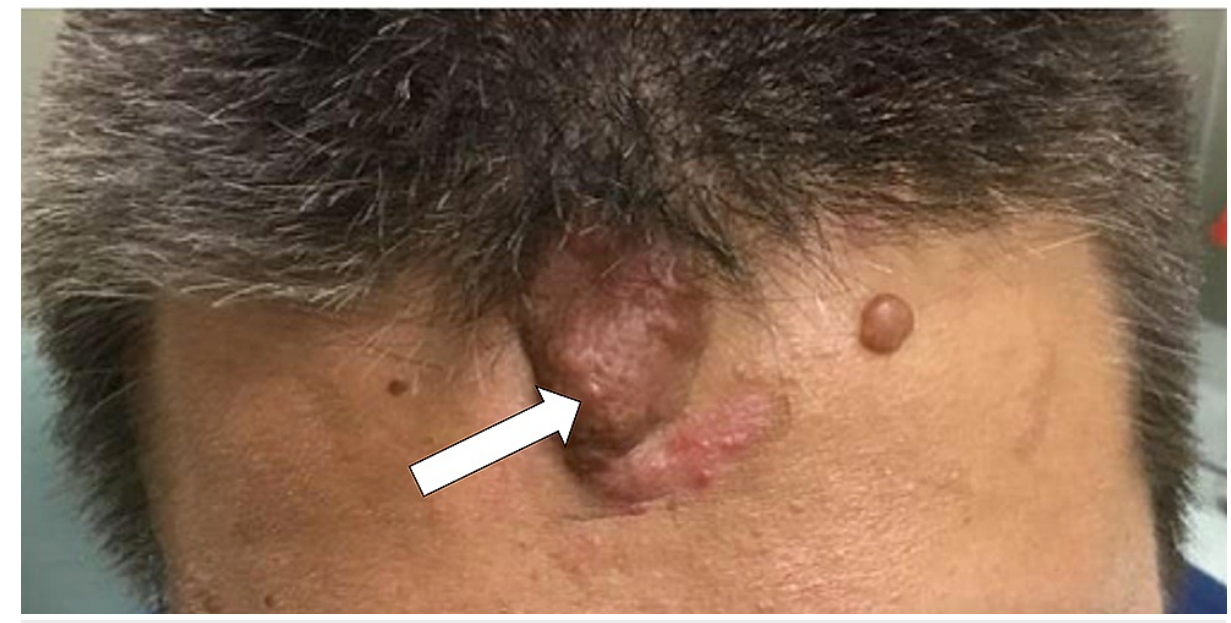

FIGURE 1: Clinical presentation of fibrous cephalic plaque on the forehead of a 17-year-old male.

View of a large exophytic mass on the central forehead with prominent comedones (white arrow). 


\section{Cureus}

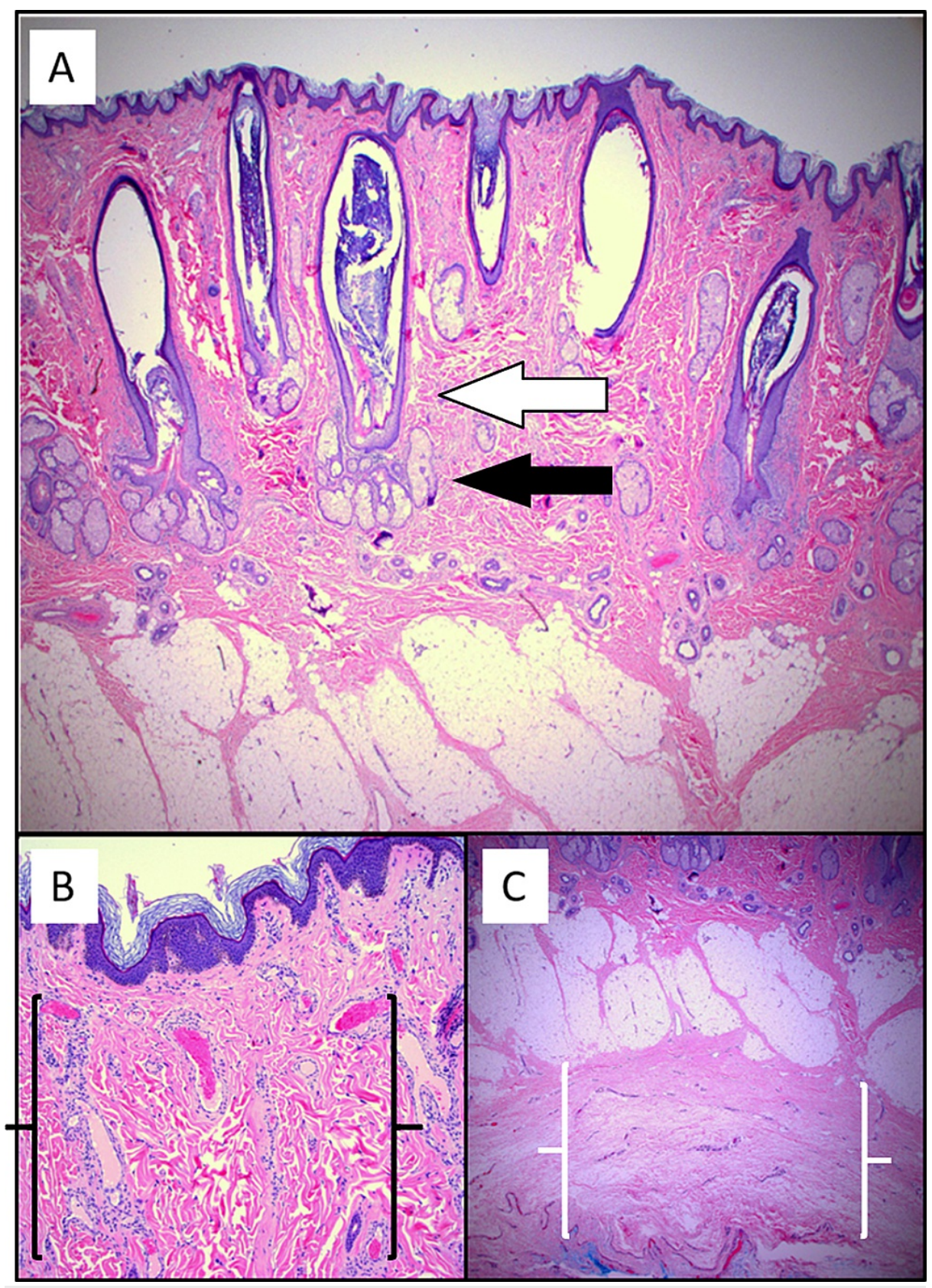

FIGURE 2: Photomicrograph of the exophytic forehead lesion stained with hematoxylin and eosin

(A) Dilated, cystic hair follicles (white arrow) with hyperplastic sebaceous glands displaced to the lower portion of the dermis (black arrow). (B) Increased vascularity and fibrocytes (black brackets). (C) Expansion of subcutaneous collagen (white brackets) underlying normal adipose tissue.

Three previous excisions taken from similar nodules on the scalp showed follicular cysts which had ruptured and an associated granulomatous inflammatory reaction and perifollicular fibrosis (Figure 3). The nodules were initially diagnosed as dissecting cellulitis, but on review, at the time of subsequent biopsies, they were found to meet the criteria for a diagnosis of FCP with cyst formation. 


\section{Cureus}

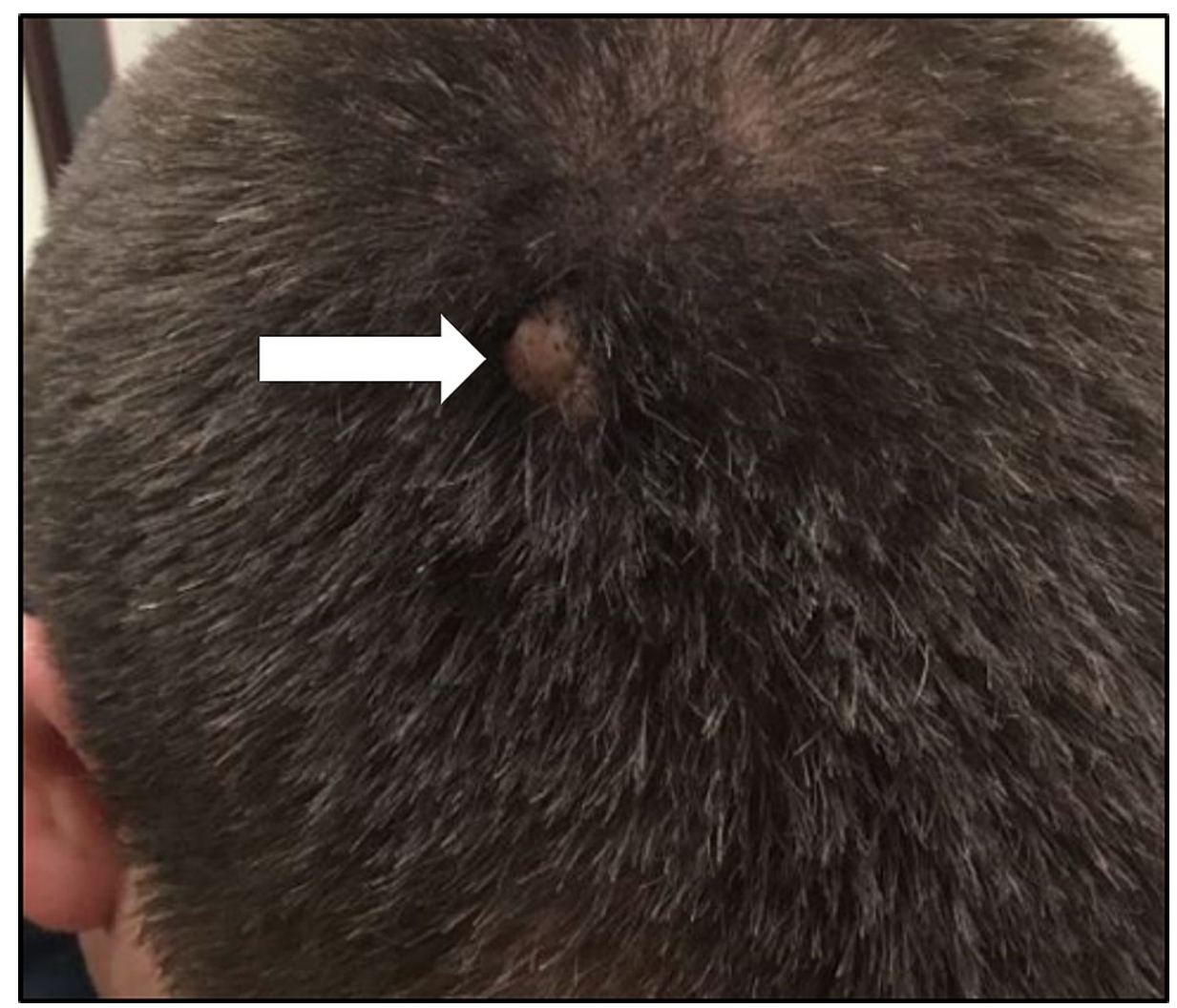

\section{FIGURE 3: Clinical presentation of FCP with cyst formation previously}

confused for dissecting cellulitis on the scalp of a 17-year-old male.

Nodular lesions previously excised from the patient's scalp (white arrow).

FCP: fibrous cephalic plaque

\section{Discussion}

In 2012, FCCH was formally described as a new, diagnostically unique hamartoma to be associated with TSC. However, some authors have called into question whether FCCH is truly distinct from FCP due to their many clinical and histopathologic similarities [4]. Histologically, FCCH is distinguished from FCP by the presence of keratin-filled infundibular cysts [3]. On physical examination, FCP and FCCH may be difficult to distinguish, though FCCH has been reported to have comedones which may drain purulent material [3] and to be located on areas of the body not classic for FCP such as the back and thigh in approximately half of the reports [4].

The pathogenesis of cutaneous hamartomas in TSC is still being investigated. However, it has been suggested that angiofibroma, shagreen patch, ungual fibroma, and FCP develop as a result of mutations to fibroblasts [10]. It could be asserted that the presence of cysts within FCP does not change the fundamental defect in fibroblasts that cause the lesion, and therefore the addition of cysts does not warrant a distinct diagnosis.

There is an analogous example in dermatopathology where the fibroepithelial hamartomas of Birt-HoggDube syndrome, fibrofolliculomas and trichodiscomas, are now accepted to represent the same entity with a spectrum of morphological features [11]. Both are regarded to be hamartomas of the fibrous sheath of the hair follicle, the distinguishing feature between trichodiscoma and fibrofolliculoma is the presence of thin strands of follicular epithelium in the latter. The selected designation may depend on what section one reviews through a single biopsy specimen. Trichodiscoma is now regarded to be a fibrofolliculoma in which the distinctive follicular epithelial strands are lacking [11].

We speculate that cysts may be a feature of FCP, and the presence of cysts should be incorporated into the list of possible features seen in FCP. As was described in our case, these cysts may rupture, making it difficult to establish the primary diagnosis due to obliteration of primary tissue architecture by granulomatous inflammation.

While FCP is not an optimal term to represent lesions outside of the cephalic distribution where some FCCH 
lesions have been reported, the presence of these lesions on non-cephalic, hair-bearing locations of the body alone does not warrant a distinct diagnosis. The diagnosis of TSC requires a combination of major and/or minor diagnostic features of which there are 11 and six, respectively (Table 1) [12].

\begin{tabular}{|l|l|}
\hline Major Criteria & Minor Criteria \\
\hline Hypomelanotic macules (3, at least 5-mm diameter) & "Confetti" skin lesions \\
Angiofibromas (3) or fibrous cephalic plaque & Dental enamel pits (3) \\
Ungual fibromas (2) & Intraoral fibromas (2) \\
Shagreen patch & Retinal achromic patch \\
Multiple retinal hamartomas & Multiple renal cysts \\
Cortical dysplasias & Nonrenal hamartomas \\
Subependymal nodules & \\
Subependymal giant cell astrocytoma & \\
Cardiac rhabdomyoma & \\
Lymphangioleiomyomatosis (LAM) & \\
Angiomyolipomas & \\
\hline
\end{tabular}

TABLE 1: Major and minor diagnostic criteria for tuberous sclerosis complex.

Importantly, FCP is a well-known major diagnostic feature of TSC. Because FCP is a more well-established manifestation of TSC, we suggest that lesions that meet the diagnostic criteria for FCP or FCCH simply be described as FCP.

\section{Conclusions}

Here, we presented a case of FCP with histologic findings of infundibular cysts in a patient with known TSC. To further complicate the diagnosis of TSC with a separate entity called FCCH simply due to the histologic presence of cysts is unnecessary. Analogous examples exist in dermatopathology in the context of the hamartomas trichodiscoma and fibrofolliculoma in Birt-Hogg-Dube syndrome. In conclusion, we see no reason to complicate the spectrum of cutaneous hamartomas with a new entity called FCCH.

\section{Additional Information \\ Disclosures}

Human subjects: Consent was obtained or waived by all participants in this study. Conflicts of interest: In compliance with the ICMJE uniform disclosure form, all authors declare the following: Payment/services info: All authors have declared that no financial support was received from any organization for the submitted work. Financial relationships: All authors have declared that they have no financial relationships at present or within the previous three years with any organizations that might have an interest in the submitted work. Other relationships: All authors have declared that there are no other relationships or activities that could appear to have influenced the submitted work.

\section{References}

1. Hake S: Cutaneous manifestations of tuberous sclerosis. Ochsner J. 2010, 10:200-204.

2. Oyerinde O, Buccine D, Treichel A, Hong C, Lee CR, Moss J, Darling TN: Fibrous cephalic plaques in tuberous sclerosis complex. J Am Acad Dermatol. 2018, 78:717-724. 10.1016/j.jaad.2017.12.027

3. Torrelo A, Hadj-Rabia S, Comenero I, et al.: Folliculocystic and collagen hamartoma of tuberous sclerosis complex. J Am Acad Dermatol. 2012, 66:617-621. 10.1016/j.jaad.2011.04.002

4. Reolid A, Navarro R, Daudén E, Alonso-Cerezo MC, Fraga J, Llamas-Velasco M: Facial folliculocystic and collagen hamartoma: a variant of fibrous cephalic plaque with prominent cyst formation?. J Dtsch Dermatol Ges. 2019, 17:738-741. 10.1111/ddg.13867

5. Kaplan L, Kazlouskaya V, Ugorji R, Heilman E, Siegel DM, Glick SA: Folliculocystic and collagen hamartoma of tuberous sclerosis: a new case in a female patient and review of literature. J Cutan Pathol. 2018, 45:67-70. 10.1111/cup.13056

6. Brown MM, Walsh EJ, Yu L, Smidt AC: Progressive scalp plaque in a girl with tuberous sclerosis . Pediatr Dermatol. 2014, 31:249-250. 10.1111/pde.12015 


\section{Cureus}

7. An JM, Kim YS, Park YL, Lee S: Folliculocystic and collagen hamartoma: a new entity? . Ann Dermatol. 2015, 27:593-596. 10.5021/ad.2015.27.5.593

8. Bishnoi A, Tripathy S, Vinay K, De D, Parsad D, Chatterjee D, Saikia UN: Image gallery: folliculocystic and collagen hamartoma: a lesser-known presentation of tuberous sclerosis. Br J Dermatol. 2018, 178:e276. 10.1111/bjd.16359

9. Cardona R, Cancel-Artau KJ, Carrasquillo OY, Martin-Garcia RF: Folliculocystic and collagen hamartoma: a distinct hamartoma associated with tuberous sclerosis complex. Am J Dermatopathol. 2021, 43:67-70. 10.1097/DAD.0000000000001720

10. Bongiorno MA, Nathan N, Oyerinde O, et al.: Clinical characteristics of connective tissue nevi in tuberous sclerosis complex with special emphasis on shagreen patches. JAMA Dermatol. 2017, 153:660-665. 10.1001/jamadermatol.2017.0298

11. Tong Y, Schneider JA, Coda AB, Hata TR, Cohen PR: Birt-Hogg-Dubé syndrome: a review of dermatological manifestations and other symptoms. Am J Clin Dermatol. 2018, 19:87-101. 10.1007/s40257-017-0307-8

12. Northrup H, Krueger DA, International Tuberous Sclerosis Complex Consensus Group: Tuberous sclerosis complex diagnostic criteria update: recommendations of the 2012 International Tuberous Sclerosis Complex Consensus Conference. Pediatr Neurol. 2013, 49:243-254. 10.1016/j.pediatrneurol.2013.08.001 